\title{
Public Health Aspect of Migrations
}

\section{Obradović Z* and Slatina E}

University of Sarajevo, Bosnia and Herzegovina

*Corresponding author: Obradović Z, University of Sarajevo, B.M. Selimovica 4571000

Sarajevo, Bosnia and Herzegovina, Tel: +387 61216291; Email: zobradovic9@gmail.com

\section{Mini Review \\ Volume 4 Issue 1}

Received Date: January 29, 2020

Published Date: February 18, 2020

DOI: $10.23880 /$ eij-16000137

\section{Abstract}

Migration is a global population movement in almost all the world, affecting all segments of social life. Of particular importance is the impact of migration on public health, which is reflected as an increase of morbidity of migrants and of the local population in countries where migrants pass through or in which they finally reside.

The occurrence of illness in migrants is related to the individual characteristics of persons who are migrants (age, gender, health and hygiene and cultural habits), the reasons why they migrate, the type of migration (legal-illegal), the transportation mode as well as the season in which migrations occur.

Migrants suffer from various diseases; the most common are infectious diseases as consequences from poor accommodation and hygiene conditions (scabies, pediculosis), diseases associated with injuries (blood borne diseases) and vaccinepreventable diseases.

A large number of migrants are burdening for the local health systems that are planned and capacitated for the local population.

Keywords: Migration; Impact on health; Diseases

\section{Introduction}

Migrations are movements of people and changes of place of residence, both in country, as well as outside country. According to this definition, migrants are persons who temporarily or permanently leave their home. The United Nations High Commissioner for Refugees (UNHCR) estimated that, by the end of 2014, some 59,5 million people were forcibly displaced, this represents the highest number of migrants recorded since World War II. In line with the above-mentioned, it is estimated that, in 2015, the number of international migrants was 244 million. Unfortunately, this number has a tendency of constant increase, thus it is estimated that it will reach 405 million by 2050 . The problem of migrants and migrations becomes even greater if this number is added to the number of about 740 million "internal" migrants, i.e. persons displaced within their own country, so the total number of people on the move exceeds one billion [1].

\section{Method}

This article is a review of main public health aspects of migrations published in the scientific journals from 2015.to 2018. and in official UNHCR and WHO reports.

\section{Results}

At the global level, migrations are more and more frequent, so it is estimated that about $3.6 \%$ of world population live outside their country of birth. The largest number of migrants is from low-income countries, i.e. they come from poor living conditions and are therefore associated with an increased incidence of infectious diseases [2].

Migrations are present all over the world, including B\&H. 


\section{Epidemiology International Journal}

The population of Bosnia and Herzegovina (B\&H) migrates within the country, and migrations to Western Europe and America are on increase more and more. At the same time, Bosnia and Herzegovina is on the migrant route of migrants coming from Syria, Afghanistan, Pakistan and some African countries. It is estimated that some 23000 migrants passed through Bosnia and Herzegovina during 2018, most of whom continued their journey to Western European countries, with only a small number of them remaining in $\mathrm{B} \& \mathrm{H}$.

The causes of migration are very different, and most often the population migrates for economic, political reasons, or is forced to migrate by various natural disasters. Migrants' health, i.e. exposure to illnesses and their morbidity depends on a series of factors, one of them is very important reason why they migrate [3].

\section{Types of Migrations}

Migrations are roughly divided into three groups: traditional - one-way, two-way, repeated, i.e. circular migrations and daily migrations. In addition to these determinants relating to the mode of migration, it is very important whether or not migrations are planned, i.e., accepted by host country. The first category, i.e. planned migrations are often referred to as legal ones, while unplanned migrations are called illegal ones. This is one of the most important determinants of migrations, which has the greatest impact on the health of migrants [4].

Migrations affect the health status of migrants, as well as of local population in all countries that are in any way related to migrations. In terms of migration, countries are classified as countries of: emigration, immigration, transit and return.

Migration-caused illnesses depend on whether travel is inland, within a region, continent, or intercontinental.

In terms of length of duration, migrations may be temporary, such as most commonly various types of seasonal, work-related migrations or permanent ones. Also, a large number of illnesses, firstly infectious ones, but also some non-infectious ones, depend on the season of migration, which is a consequence of exposure to various types of agents and environmental risk factors.

\section{Consequences of Migrations}

The term "mobility" refers primarily to the physical displacement of persons, but this term includes also mobility of cultures, mobility of health (and hygiene) habits, as well as mobility of epidemiological factors and risks.

If one starts from the fact that the right to health is one of the basic human rights, that should be accessible to everyone, it would mean that even migrants may exercise that right, i.e. that they have access to health care. In practice, the situation is often completely different, and migrants often have no access to health care or, in some situations they have access to a minimum set of services. Access to existing health services in host country depends on the legal status of migrants. Health services are different in different countries, so it happens that migrants in host country are offered better and more comprehensive health care that in their home country. However, significantly more often, migrants have poor or limited access to health care, sometimes significantly worse than in country they come from.

Access to health care and exercise of their right to health is a particularly big problem for illegal migrants. However, even legal migrants, who come to a country where they have health insurance, do not have full access to health care, unlike the locals who have it, and the main reasons are the problems due to cultural barriers, or very often due to language barriers. An additional problem is generally insufficient information for migrants about their rights, including also rights in the field of health care.

Despite all the efforts of host countries and different organizations fighting for the rights of migrants, it is difficult to achieve the objective of reducing or completely eliminating the difference in access to health services for migrants and local population. As a result, a special area of health sciences called "migration health" has developed. It deals with the health of migrants and local population, both in countries of transit and in final destination.

\section{Factors Affecting Migrant Morbidity}

Migrant morbidity depends on several factors, the most important of which are: personal characteristics of migrants, reasons that led to migrations, types of migration from legal aspect, ways of migrant movement, and season in which migrations take place. Each of these factors has its own significance and influence on occurrence of certain illnesses and their spread amongst migrant population, and from migrants to local population and vice versa. The onset of illness depends most on individual characteristics of migrants.

Migrant's Individual Characteristics are Age, Gender, Health Condition, Hygiene and Cultural Habits: The age of migrants depends on type of migration, so in economic migrations, migrants are a working age population, at least in the first phase of migration. Migrations for political reasons or for wars, among migrants include persons of all ages, except for oldest persons. Sometimes entire families migrate, which is a lot easier, from the aspect of psychological support, than 


\section{Epidemiology International Journal}

migration of individual family members. Minor migrants who are not accompanied by their parents or guardians represent a particular problem. Age significantly determines type of illness that migrants suffer from, so knowing their age groups is crucial to planning and implementing health care of migrants.

More recently, migrants are persons of both genders, but still there are more men than women among migrants.

Migrants are persons of different health status. These can be healthy persons, with good immunity, but also persons with various diseases: acute, chronic, somatic, psychological ones. When it comes to infectious diseases, it is important to mention also the possibility that migrants carry the germs and spread pathogens in the environment, which leads to emergence of disease in other susceptible persons.

It is of utmost importance to emphasize the fact that migrations represent a major stress for migrants, and this is what can be also reflected on morbidity. So, in the beginning, a strong stress has protective effect and mobilizes all forces in body, thus migrants feel well, sometimes even better than before migrations. For instance, persons who have high blood sugar level, at the beginning of migration have normalized values, although they do not take therapy on a regular basis, and some persons do not take it at all [5].

However, stress can be a major problem in latent psychiatric diseases and lead to manifestation of serious psychiatric disorder states that have not occurred previously to that person. Due to stress, various, completely inappropriate actions are possible, which can be fatal for persons from surrounding or for sick person.

Reasons for Migration: Migrant morbidity is linked to the reasons why migrations occur. Most often, they are: work, marriage conclusion, family reunion, escape from war or escape from law. Migrations for work, marriage conclusion or family reunion have usually positive effect on migrants, so the impact of stress is not pronounced. Nevertheless, even these migrations lead migrants to some new circumstances and exposure to some new, until that moment unknown factors, resulting in onset of the morbidity [3].

Migrations due to wars or escape from law carry a high risk of morbidity, because migrants are under severe stress and do not know what awaits them in the future, they go into uncertainty.

Types of Migration from Aspect of Law (Legal, Illegal Ones): The onset of the disease, but also provision of health care to migrants, depends on whether migrations are legal or illegal from the aspect of law.
Legal migrations (due to work, family reunion) do not have to have any consequences for the health of migrants. These migrations are carried out by adequate transport means, so travel from country the persons emigrates from to the country the persons immigrates to takes a short time, it is often comfortable (for instance travel by plane with family). This category of migrants knows what to expect in the country they migrate to, most commonly, in the final destination, work and flat are provided.

In spite of all the positive aspects that accompany legal migrations, even this category of migrants may have difficulties in obtaining health care, and this happens most commonly due to language and cultural barriers.

Illegal migrations have a major impact on the health of migrants. Most often, it is about separation from family and going into uncertainty. Illegal migrants often do not know even where they go, i.e. what is their final destination, but they decide about it while traveling. Illegal migrants use various transport means, and often they walk on forest paths, in order to stay away from police bodies. Their journeys are often very risky and migrants are exposed to high risk of different disease onset. First and foremost, migrants are often unaware of their rights, they do not know whether they are entitled to health care and, if so, what that care includes.

Ways of Migration by type of Transport: Ways of migration depend on migrant's legal status, economic power of country and migrant's economic power. Mostly migrations use all available transportation means: cars, trains, ships. Unfortunately, a large number of illegal migrants go on foot.

Ways of migration influence morbidity as per two criteria, and they are: length of travel and conditions during travel. The migratory travel lasts longer and the conditions during travel are worse, the migrants are more exhausted and there are more chances for onset of different diseases.

Different risks are associated with different means of transport. So when travelling by (rubber) ships and boats, there is a high risk of drowning. Walking has a high risk of injury or various types of robbery and maltreatment.

In general, migrants are often exposed to various types of torture and maltreatment, and often to extortion of sexual services in exchange for transport to a particular destination [6].

Season in which Migrations Occur: Migrants are a particularly vulnerable group of population during the time of migration, as well as when they arrive to certain destination. The first months of life in some new country most 


\section{Epidemiology International Journal}

often are spent in inadequate accommodation conditions (overcrowded, improvised accommodation facilities), inadequate conditions for maintaining personal hygiene and inadequate nutrition. That is why seasonal diseases are significantly more common among migrants than among local population.

Thus, in winter, migrants often suffer from respiratory diseases, and during summer they suffer from diseases caused by contaminated food consumption. The incidence of type A viral hepatitis is significantly higher among migrants compared to local population.

Key Migration Issues: Migrants are exposed to various types of problems and risks. In order to create minimum living conditions for migrants, it is necessary to provide for them: hygienically safe water (for drinking, maintaining hygiene), sufficient quantities of adequate food, adequate accommodation conditions, clothing and footwear adapted to conditions in country they immigrated to. It is also very important to give them the information on access rights to health care and to provide them (without language barriers) with basic set of medical services.

Most Common Diseases among Migrants: Non-infectious and infectious diseases affect the migrants, as well as the rest of population. As far as mass non-infectious diseases are concerned, they are the same as in the stationary population. However, there are certain differences in the incidence of infectious diseases and they are more common in migrants compared to local population $[6,7]$.

The most common infectious diseases in migrants are those transmitted by water and food, followed by respiratory diseases, among which TB is particularly important because of exhaustion. The next category is parasitic diseases, primarily scabies and pediculosis, which occur in overcrowded accommodation. Due to frequent injuries, but also maltreatment, migrants suffer from blood-borne diseases (VHB, VHC), and sexually transmitted diseases (VHB, HIV, syphilis, gonorrhea) [6].

Recent years, attention has been drawn to increasingly important HIV and tuberculosis co-infection, and this is due to migrants' exhaustion and poor nutrition $[7,8]$.

Depending on the development and health care programs in countries migrants come from, there is a risk that migrants are not vaccinated [9].

Most migrants do not have their health booklet, thus their vaccination status is unknown. For these reasons, migrants are at risk for vaccine-preventable diseases, and there is a risk of transmitting these diseases to non-immunized local population $[10,11]$.
Impact of Migrations on Local Population's Health: Migrations are a public health problem, because of morbidity of a large number of people, migrants, but also local population. From their country or from country on transit route, migrants bring new agents into host country. These agents are often unknown to local population.

Migrants significantly increase the number of people at certain locations, which causes overcrowding and all the diseases that come with overcrowding. Each area plans and develops its services, including health care ones in accordance with population needs. The arrival of migrants (often in a large number) leads to sudden overload of service. From the health care aspect, that means significantly larger number of requests for health care service, significantly greater needs for all types of resources (personnel, equipment, reagents, medicines). Most communities are not able to provide for a long time significantly larger number of services, since they get exhausted and spend all types of resources, thus no needed health care may be provided, not only to migrants, but to local population with health insurance neither $[2,12]$.

\section{Conclusion}

Migrations are a growing movement of population and there is almost no country in the world that is somehow unaffected by this social phenomena. From the aspect of migrants' health care, but also entire population, a global approach to public health is needed. Strengthening public health care system is of great importance, as well as integrating information from country of origin, transit countries and host countries.

Strengthening mechanism for disease monitoring and establishing prompt response to onset of epidemics, - these are important issues too.

It is necessary to strengthen health care systems and make them capable of enabling migrants' access to health care systems at all levels.

\section{References}

1. UNHCR global trends: forced displacement 2014 ward at war (2015) Geneva: United Nations High Commissioner for Refugees.

2. Heywood AE, Lopez-Velez R (2018) Reducing infectious disease inequities among migrants. J Travel Med 26(2).

3. Kentikelenis A, Karanikolos M, Williams G, Mladovsky P, King L, et al. (2015) How to economic crises affect migrants risk of infectious disease? A systematic narrative review. Eur J Public Health 25(6): 937-944. 


\section{Epidemiology International Journal}

4. Oyebode O, Pape UJ, Laverty AA, Lee JT, Bhan N, et al. (2015) Rural, urban and migrant differences in noncommunicable disease risk-factors in middle income countries: a cross-sectional study of WHO-SAGE data. PloS One 10(4): e0122747.

5. Eikemo TA, Gkiouleka A, Rapp C, Skjonne Utvei S, Huijts T, et al. (2018) Non-communicable diseases in

Greece: inequality, gender and migration. Eur J Public Health 28(5): 38-47.

6. Cuomo G, Franconi I, Riva N, Bianchi A, Digaetanoat Mal, et al. (2018) Migration and health: A retrospective study about theprevalence of HBV, HIV, HCV, tuberculosis and syphilis infections amongst newly arrived migrants screened at the Infectious Diseases Unit of Modena, Italy. J Infect Public Health12 (2): 200-204.

7. Silvestre E, Weiner R, Hutchinson P (2015) Behavior change communication and mobile populations: the evaluation of a cross-border HIV/AIDS communication strategy amongst migrants from Swaziland. AIDS Care
28 (2): 214-220.

8. Castelli F, Sulis G (2017) Migration and infectious diseases. Clin Microbiol Infect 23(5): 283-289.

9. Gialbi C, Del Manso M, Dente MG, Napoli C, MontañoRemacha C, et al. (2017) Immunization Strategies Targeting Newly Arrived Migrants in Non EU Countries of theMediterranean Basin and Black sea. Int J Environ Res Public Health 14(5): 459.

10. Ravensbergen SJ, Nellums LB, Hargreaves S, Stienstra Y, Friedland JS, et al. (2018) Nationalapproaches to thevaccination of recently arrived migrants in Europe: A comparative policy analysis across 32 European countries. Travel Med Infec Dis 27: 33-38.

11. Mipatrini D, Stefanelli P, Rezza G, Severoni S (2017) Vaccinations in migrants and refugees: a challenge for European health systems. A systematic review of current scientific evidence. Pathog Glob Health 111(2): 59-68.

12. WHO (2008) Migrant health. 